\title{
Dual-band bandpass filter based on two u-shaped defected microstrip structure
}

\author{
Mussa Mabrok ${ }^{1}$, Zahriladha Zakaria ${ }^{2}$, Yully Erwanti Masrukin ${ }^{3}$, Tole Sutikno ${ }^{4}$ \\ ${ }^{1,2,3}$ Center for Telecommunication Research and Innovation (CeTRI), Faculty of Electronics and Computer Engineering, \\ Universiti Teknikal Malaysia Melaka (UTeM), Hang Tuah Jaya, 76100 Durian Tunggal, Melaka, Malaysia. \\ ${ }^{4}$ Department of Electrical Engineering, Universitas Ahmad Dahlan, Indonesia
}

\begin{tabular}{l} 
Article Info \\
\hline Article history: \\
Received Jan 20, 2021 \\
Revised Mar 29, 2021 \\
Accepted Apr 6, 2021 \\
\hline
\end{tabular}

\section{Keywords:}

Bandpass filter

DMS

Dual-band

Microstrip filter

Wireless application

\begin{abstract}
This paper presents design of dual-band bandpass filter by integrating conventional quarter-wavelength short circuit stubs bandpass filter with Ushaped defected microstrip structure notch filter. Based on the parametric analysis, it is found that high attenuation level can be achieved by using two U-shaped defected microstrip structure separated by specific distance. The designed circuit simulated using advanced design system and fabricated based on Roger 4350B. The simulation results are in good agreement with measured results. The designed filter covered two pass bands centered at 2.51 $\mathrm{GHz}$ and $3.59 \mathrm{GHz}$ with $3-\mathrm{dB}$ fractional bandwidth of $15.94 \%$ and $15.86 \%$, respectively, return losses better than $15 \mathrm{~dB}$, and insertion losses better than $1 \mathrm{~dB}$. The designed device can be used for wireless communication applications such as WLAN and WiMAX.
\end{abstract}

This is an open access article under the CC BY-SA license.

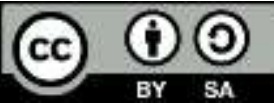

\section{Corresponding Author:}

Zahriladha Zakaria

Center for Telecommunication Research and Innovation (CeTRI)

Faculty of Electronics and Computer Engineering

Universiti Teknikal Malaysia Melaka (UTeM)

Hang Tuah Jaya, 76100 Durian Tunggal, Melaka, Malaysia

Email: zahriladha@utem.edu.my

\section{INTRODUCTION}

Microwave filters are needed in wireless communication systems to allow passing wanted signals and attenuate an unwanted signals. Previously, single-band filter which can only operates in single frequency band is used. To fulfil user end requirements, multi band microwave filter which can be supported in a single device are needed. A single device has capability to operate in multiple frequencies and support various wireless communication systems such as GSM, WLAN, and WiMAX is highly demanded [1]-[5]. Different approaches of designing multi-band bandpass filter (BPF) have been proposed in [6]-[22] to realize compact size and optimize the performance. However, they still suffer from some limitations such as high insertion loss as in [6]-[7], [12], narrow bandwidth as in [17], [19]-[20], and large size as in [16]. Therefore, to overcome the aforementioned problems and maintain a compact size. Integration of quarter-wavelength short-circuited stubs bandpass filter and U-shaped defected microstrip stracture (DMS) is proposed in the work. The proposed structure has many advantageous. First, BPF based on Quarter-wavelength short-circuit stubs can achieve wide bandwidths. Second, DMS does not occupy additional area as it is based on inserting slots into the microstrip line of BPF. The proposed design achieves two pass bands centered at 2.51 and 3.59 $\mathrm{GHz}$ with return loss better than $15 \mathrm{~dB}$ and insertion loss better than $1 \mathrm{~dB}$. The design is verified by 
simulations using advanced design system (ADS) and measurements using vector network analyzer (VNA). Measured results shows a good agreement with the simulations.

\section{RESEARCH METHOD}

The design process started with designin five sections quarter-wavelength $(\lambda / 4)$ short circuit stubs $\mathrm{BPF}$, followed by designing U-shaped DMS notch filter. Then, integration between U-shaped DMS and BPF to produce dual-band BPF. Parametric analysis is conducted based on both the position and number of Ushaped DMS in order to assess the performance of the designed filter.

\subsection{Wideband bandpass filter}

Conventional $\lambda / 4$ short circuited stubs BPF is commonly used in the RF/Microwave applications [23]. First of all, the degree of the low pass prototype, $\mathrm{N}$ and the ratio of stopband and passband bandwidth, $\mathrm{S}$ is calculated using (1) and (2).

$$
\mathrm{N} \geq \frac{\mathrm{L}_{\mathrm{A}}+\mathrm{L}_{\mathrm{R}}+6}{20 \log _{10}\left[\mathrm{~S}+\left(\mathrm{S}^{2}-1\right)^{1 / 2}\right]}
$$

Where, $L_{A}=$ Stopband insertion loss, $L_{R}=$ Passband return loss. $S=$ Ratio of stopband to passband bandwidth And the ratio of stopband and passband bandwidth can be calculate using (2);

$$
\begin{aligned}
& \mathrm{S}=\frac{\text { Passband Bandwidth }}{\text { Stopband Bandwidth }}=\frac{3.9}{2.3}=1.696 \\
& \text { Therefore, } N \geq \frac{1+15+6}{20 \log _{10}\left[1.696+\left(1.696^{2}-1\right)^{\frac{1}{2}}\right]}=4.78 \sim 5
\end{aligned}
$$

The modeling circuit of the proposed wideband bandpass filter is illustrated in Figure 1. The model of bandpass filter comprises of 5 th order shunt short stubs in length of $\lambda \mathrm{g} / 4$ with the connecting lines. The $\lambda_{\mathrm{g}}$ is the guided wavelength in the medium of propagation at the mid-band frequency, $f_{0}$. Table 1 shows the specifications of wideband bandpass filter based on quarter-wavelength short circuit stubs.

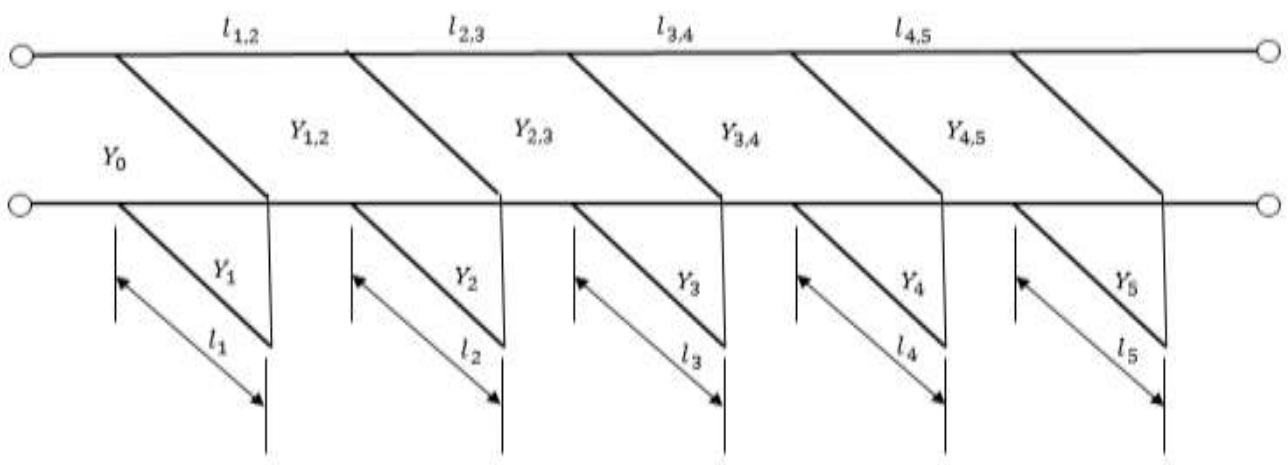

Figure 1. Modeling circuit of the proposed wideband bandpass filter

Table 1. Specifications of bandpass filter

\begin{tabular}{cc}
\hline \multicolumn{2}{c}{ Bandpass Filter Specification } \\
\hline Frequency Band & $2.3-3.9 \mathrm{GHz}$ \\
Fractional Bandwidth, $F B W$ & $51.61 \%$ \\
Stopband Insertion Loss, $L_{A}$ & $0.3 \mathrm{~dB}$ \\
Passband Return Loss, $L_{R}$ & $>20 \mathrm{~dB}$ \\
\hline
\end{tabular}

Based on the modeling circuit in Figure 1, all the obtained values of admittances and impedances for five short-circuited stubs $\left(Y_{i}\right.$ and $\left.Z_{i}\right)$ and transmission lines $\left(Y_{i, i+1}\right.$ and $\left.Z_{i, i+1}\right)$ are tabulated in Table 2. The tabulated impedances and admittances can be calculated using the following equations: 


$$
\begin{aligned}
& \frac{\mathrm{J}_{1,2}}{\mathrm{Y}_{0}}=\mathrm{g}_{0} \sqrt{\frac{\mathrm{hg}_{1}}{\mathrm{~g}_{2}}}=(1) \sqrt{\frac{(2)(1.468)}{(1.3712)}}=1.2933 \\
& \frac{\mathrm{J}_{2,3}}{\mathrm{Y}_{0}}=\frac{\mathrm{hg}_{0} \mathrm{~g}_{1}}{\sqrt{\mathrm{g}_{2} \mathrm{~g}_{3}}}=\frac{(2)(1)(1.468)}{\sqrt{(1.3712)(1.9750)}}=1.3937 \\
& \frac{\mathrm{J}_{3,4}}{\mathrm{Y}_{0}}=\frac{\mathrm{hg}_{0} \mathrm{~g}_{1}}{\sqrt{\mathrm{g}_{3} \mathrm{~g}_{4}}}=\frac{(2)(1)(1.468)}{\sqrt{(1.9750)(1.3712)}}=1.3937 \\
& \frac{\mathrm{J}_{4,5}}{\mathrm{Y}_{0}}=\frac{\mathrm{hg}_{0} \mathrm{~g}_{1}}{\sqrt{\mathrm{g}_{4} \mathrm{~g}_{5}}}=\frac{(2)(1)(1.812)}{\sqrt{(1.5734)(2.0967)}}=1.30067 \\
& \frac{\mathrm{J}_{5,6}}{\mathrm{Y}_{0}}=\frac{\mathrm{hg}_{0} \mathrm{~g}_{1}}{\sqrt{\mathrm{g}_{5} \mathrm{~g}_{6}}}=\frac{(2)(1)(1.812)}{\sqrt{(2.0967)(1.4228)}}=1.3677 \\
& \frac{\mathrm{J}_{6,7}}{\mathrm{Y}_{0}}=\mathrm{g}_{0} \sqrt{\frac{\mathrm{hg}_{1} \mathrm{~g}_{8}}{\mathrm{~g}_{0} \mathrm{~g}_{6}}}=(1) \sqrt{\frac{(2)(1.1812)(1)}{(1)(1.4228)}}=1.2886
\end{aligned}
$$

where, $\mathrm{J}_{\mathrm{i}, \mathrm{i}+1}$ is the $\mathrm{J}$-inverter, $\mathrm{h}=2$ (dimensionless constant), and $g_{0}$ to $g_{8}$ are the element values for Chebyshev lowpass prototype filters.

To calculate $Y_{0}$, the $N_{1,2}$ have to be calculated first using (9):

$$
\begin{gathered}
\mathrm{N}_{1,2}=\sqrt{\left(\frac{\mathrm{J}_{1,2}}{\mathrm{Y}_{0}}\right)^{2}+\left(\frac{\mathrm{hg}_{0} \mathrm{~g}_{1} \tan \theta}{2}\right)^{2}}=\sqrt{(1.2933)^{2}+\left(\frac{(2)(1)(1.1468) \tan (1.1655)}{2}\right)^{2}}= \\
\sqrt{(1.2933)^{2}+(7.1443)^{2}}=2.9693 \\
\mathrm{~N}_{2,3}=\sqrt{\left(\frac{\mathrm{J}_{2,3}}{\mathrm{Y}_{0}}\right)^{2}+\left(\frac{\mathrm{hg}_{0} \mathrm{~g}_{1} \tan \theta}{2}\right)^{2}}=\sqrt{(1.3937)^{2}+\left(\frac{(2)(1)(1.1468) \tan (1.1655)}{2}\right)^{2}}= \\
\sqrt{(1.3937)^{2}+(7.1443)^{2}}=3.01441 \\
\mathrm{~N}_{3,4}=\sqrt{\left(\frac{\mathrm{J}_{3,4}}{\mathrm{Y}_{0}}\right)^{2}+\left(\frac{\mathrm{hg}_{0} \mathrm{~g}_{1} \tan \theta}{2}\right)^{2}}=\sqrt{(1.3937)^{2}+\left(\frac{(2)(1)(1.1468) \tan (1.1655)}{2}\right)^{2}}= \\
\sqrt{(1.3937)^{2}+(7.1443)^{2}}=2.42434 \\
\mathrm{~N}_{4,5}=\sqrt{\left(\frac{\mathrm{J}_{4,5}}{\mathrm{Y}_{0}}\right)^{2}+\left(\frac{\mathrm{hg}_{0} \mathrm{~g}_{1} \tan \theta}{2}\right)^{2}}=\sqrt{(1.30067)^{2}+\left(\frac{(2)(1)(1.1812) \tan (1.0472)}{2}\right)^{2}}= \\
\sqrt{(1.30067)^{2}+(2.0459)^{2}}=2.42434
\end{gathered}
$$

$$
\begin{gathered}
\mathrm{N}_{5,6}=\sqrt{\left(\frac{\mathrm{J}_{5,6}}{\mathrm{Y}_{0}}\right)^{2}+\left(\frac{\mathrm{hg}_{0} \mathrm{~g}_{1} \tan \theta}{2}\right)^{2}}=\sqrt{(1.3677)^{2}+\left(\frac{(2)(1)(1.1812) \tan (1.0472)}{2}\right)^{2}}= \\
\sqrt{(1.3677)^{2}+(2.0459)^{2}}=2.46099
\end{gathered}
$$

$$
\mathrm{N}_{6,7}=\sqrt{\left(\frac{\mathrm{J}_{6,7}}{\mathrm{Y}_{0}}\right)^{2}+\left(\frac{\mathrm{hg}_{0} \mathrm{~g}_{1} \tan \theta}{2}\right)^{2}}=\sqrt{(1.2886)^{2}+\left(\frac{(2)(1)(1.1812) \tan (1.0472)}{2}\right)^{2}}=
$$$$
\sqrt{(1.2886)^{2}+(2.0459)^{2}}=2.41787
$$

$Y_{1}$ is the stubs admittances and can be calculate using (15):

$$
\begin{aligned}
& Y_{1}=g_{0} Y_{0}\left(1-\frac{h}{2}\right) g_{1} \tan \theta+Y_{0}\left(N_{1,2}-\frac{J_{1,2}}{Y_{0}}\right)=(1)\left(\frac{1}{50}\right)\left(1-\frac{2}{2}\right)(1.1812) \tan (1.1655)+ \\
& \left(\frac{1}{50}\right)(2.9693-1.2933)=0.03352
\end{aligned}
$$

$Y_{i}$ can be calculate using (16) for $i=2$ to $n$

$$
Y_{2}=Y_{0}\left(N_{1,2}+N_{2,3}-\frac{J_{1,2}}{Y_{0}}-\frac{J_{2,3}}{Y_{0}}\right)=\left(\frac{1}{50}\right)(2.9693+3.01441-1.2933-1.3937)=0.06593
$$




$$
\begin{aligned}
& Y_{3}=Y_{0}\left(N_{2,3}+N_{3,4}-\frac{J_{2,3}}{Y_{0}}-\frac{J_{3,4}}{Y_{0}}\right)=\left(\frac{1}{50}\right)(3.01441+3.01441-1.3937-1.3937)=0.0648284 \\
& Y_{4}=Y_{0}\left(N_{3,4}+N_{4,5}-\frac{J_{3,4}}{Y_{0}}-\frac{J_{4,5}}{Y_{0}}\right)=\left(\frac{1}{50}\right)(2.42434+2.42434-1.30067-1.30067)=0.04495 \\
& Y_{5}=Y_{0}\left(N_{4,5}+N_{5,6}-\frac{J_{4,5}}{Y_{0}}-\frac{J_{5,6}}{Y_{0}}\right)=\left(\frac{1}{50}\right)(2.42434+2.46099-1.30067-1.36777)=0.04435 \\
& Z_{i}=\frac{1}{Y_{i}}
\end{aligned}
$$

$Y_{i, i+1}$ can be obtained by using ( 21 to 24$)$ :

$$
\begin{aligned}
& Y_{1,2}=Y_{0}\left(\frac{J_{1,2}}{Y_{0}}\right)=\left(\frac{1}{50}\right)(1.2933)=0.025866 \\
& Y_{2,3}=Y_{0}\left(\frac{J_{2,3}}{Y_{0}}\right)=\left(\frac{1}{50}\right)(1.3937)=0.027874 \\
& Y_{3,4}=Y_{0}\left(\frac{J_{3,4}}{Y_{0}}\right)=\left(\frac{1}{50}\right)(1.3937)=0.027874 \\
& Y_{4,5}=Y_{0}\left(\frac{J_{3,4}}{Y_{0}}\right)=\left(\frac{1}{50}\right)(1.30067)=0.02601 \\
& Z_{i, i+1}=\frac{1}{Y_{i, i+1}}
\end{aligned}
$$

Table 2. Design parameters of ideal bandpass filter

\begin{tabular}{ccccc}
\hline $\mathrm{i}$ & $\mathrm{Yi}(\mathrm{mhos})$ & $\mathrm{Zi}(\mathrm{ohm})$ & $\mathrm{Yi}, \mathrm{i}+1(\mathrm{mhos})$ & $\mathrm{Zi}, \mathrm{i}+1(\mathrm{ohm})$ \\
\hline 1 & 0.03352 & 29.8329 & 0.025866 & 38.6608 \\
2 & 0.06593 & 15.1666 & 0.027874 & 35.8757 \\
3 & 0.06482 & 15.4253 & 0.027874 & 35.8757 \\
4 & 0.04495 & 22.2469 & 0.02601 & 38.6608 \\
5 & 0.04435 & 22.5479 & & \\
\hline
\end{tabular}

The $Z_{1}$ to $Z_{5}$ are defined as the characteristic impedances of the short-circuited stubs while the $Z_{1,2}$ to $Z_{4,5}$ are the characteristic impedances for the connecting lines. $Z_{0}=50 \Omega$ is chosen as terminal impedance for the matching when connected to the SMA connector. Figure 2 shows the schematic of an ideal design of $5^{\text {th }}$ order bandpass filter $\lambda \mathrm{g} / 4$ short circuit stubs.

Next, the ideal design in Figure 2 is converted into microstrip design in Figure 3 by automatically converting the characteristic impedance (Z) and electrical length (E) of each transmission line into width (W) and length (L) of the microstrip lines using LineCalc tool in advanced design system (ADS). Figure 3 shows the microstrip line design, where it is built based on Roger 4350 with dielectric constant, $\epsilon_{r}=3.48$, and thickness, $\mathrm{h}=0.508 \mathrm{~mm}$.

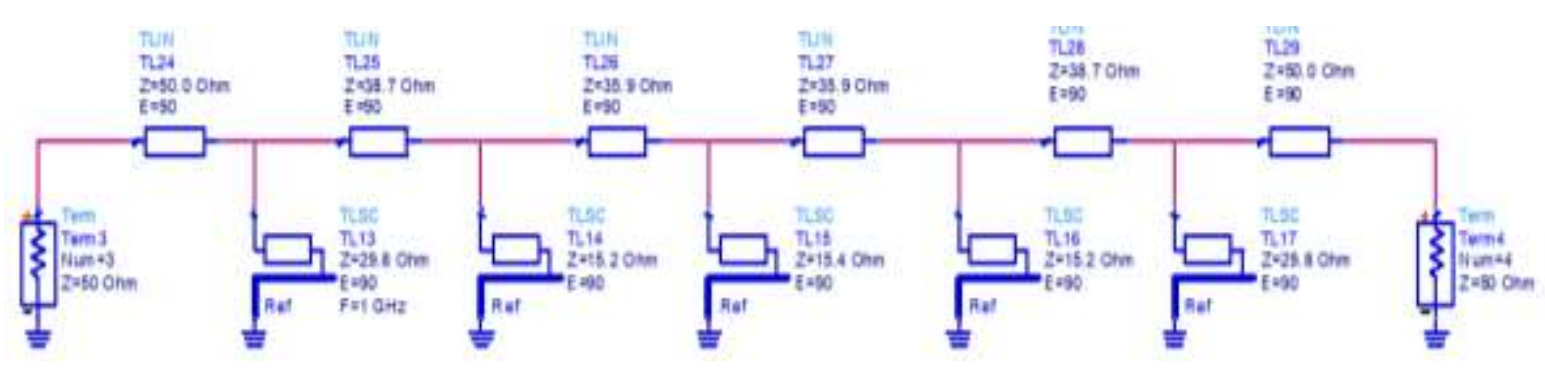

Figure 2. Ideal design of bandpass filter

Indonesian J Elec Eng \& Comp Sci, Vol. 22, No. 2, May 2021 : 909 - 918 


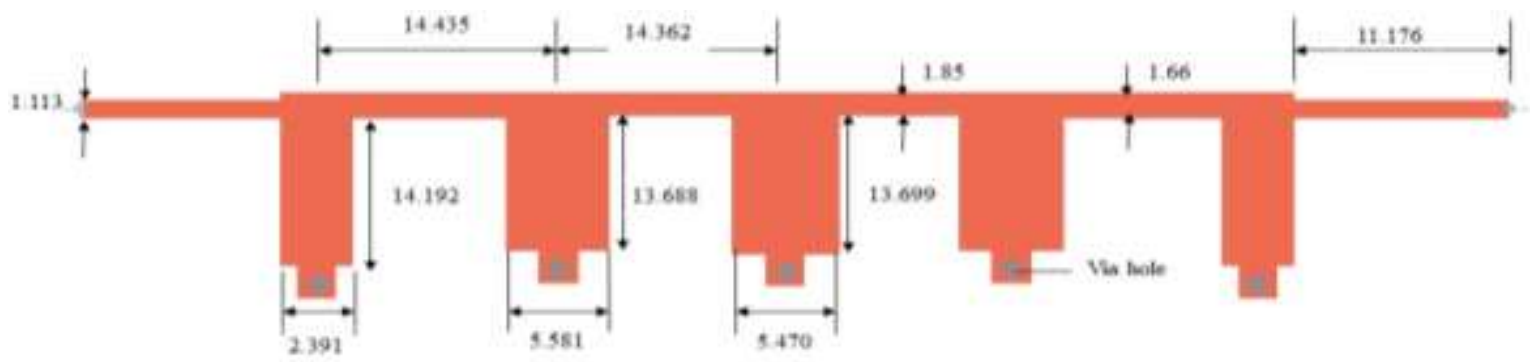

Figure 3. Microstrip bandpass filter based on five sections quarter-wavelength short circuit stubs

Figures 4(a), (b), and (c) show the effect of the length's stub on the resonance frequency of BPF. It can be observed that increasing the length's stubs will increase the return loss. The effect of the width's stubs is shown in Figures 5(a), (b), and (c). For the first, second, fourth, and fifth's stubs. As we increase the width's stubs, the return loss at the resonance frequency increases. Whereas, increasing the middle (third) stub's width will lead to decreasing the return loss.

Figure 6(a) and (b) shows the simulation results of the designed ideal and microstrip filters respectively. Good agreement can be observed with slight difference due to the substrate's losses of the microstrip design. The simulated return loss $\left(S_{11}\right)$ is better than $20 \mathrm{~dB}$ with insertion loss $\left(\mathrm{S}_{21}\right)$ of $0.01 \mathrm{~dB}$ over the frequency band 2.3-3.9 GHz. Furthermore, the designed filter yields high selectivity wideband response with fractional bandwidth $(\mathrm{FBW})$ of $51.6 \%$ at $3 \mathrm{GHz}$.

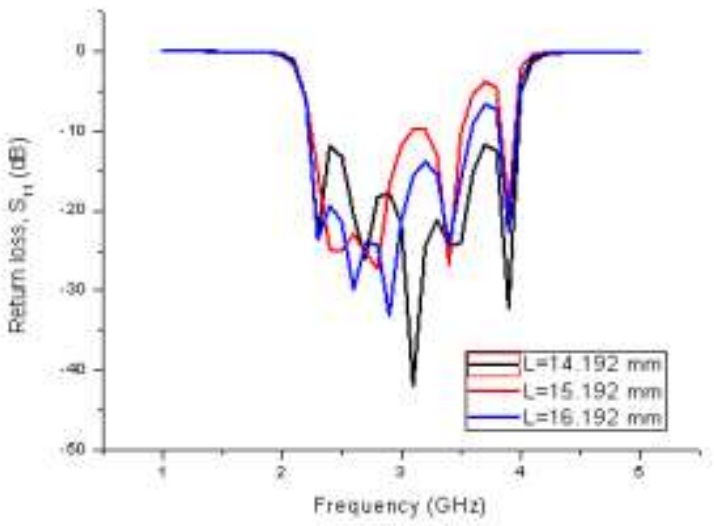

(a)

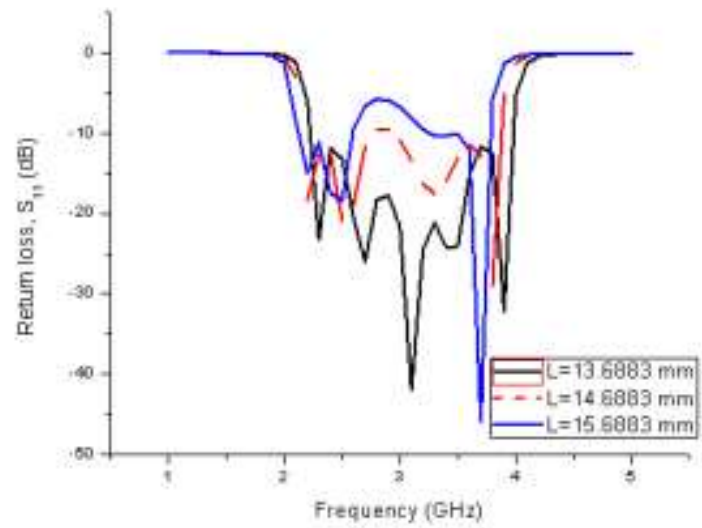

(b)

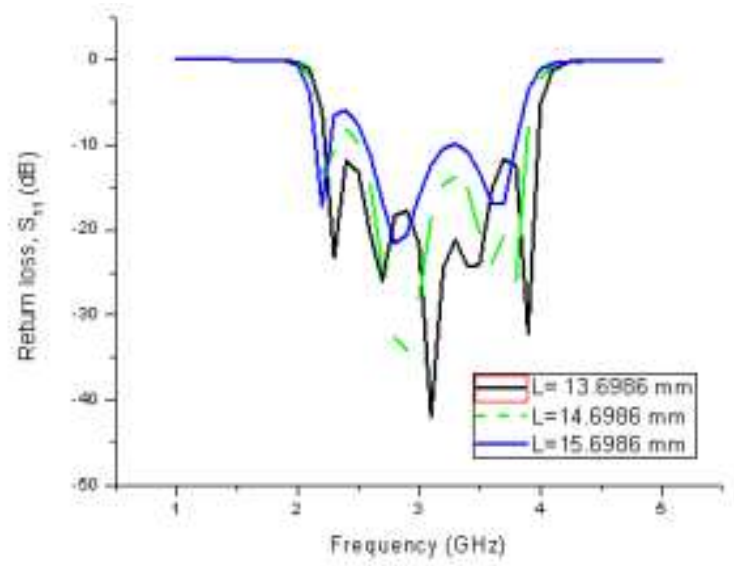

(c)

Figure 4. Parametric analysis on the effect of stub's length on the resonance frequency (a) $1^{\text {st }}$ and $5^{\text {th }}$ stub. (b) $2^{\text {nd }}$ and $4^{\text {th }}$ stub. (c) Middle stub 


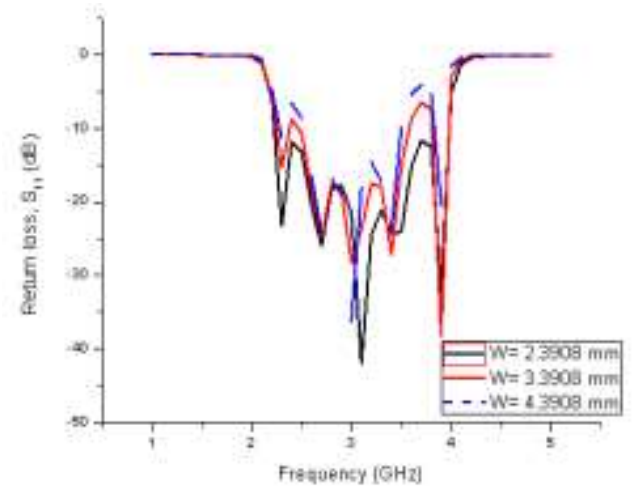

(a)

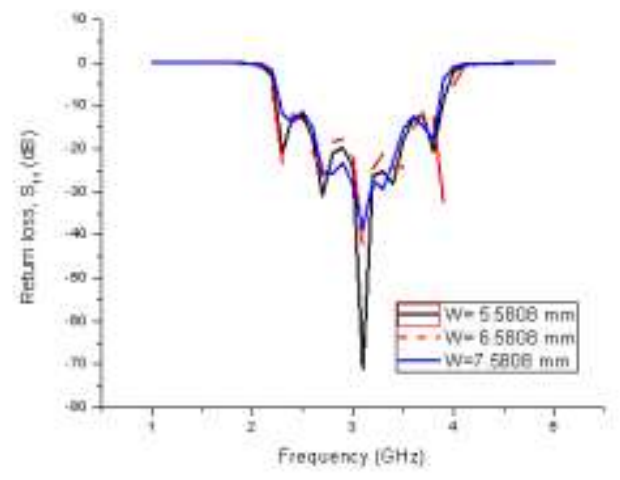

(b)

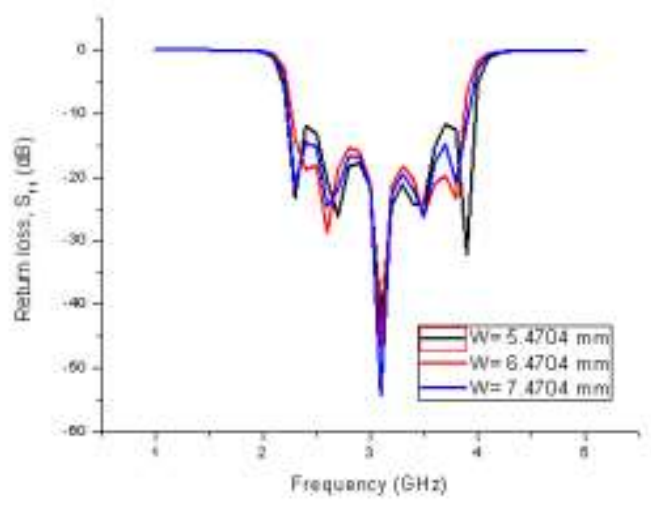

Figure 5. Parametric analysis on the effect of stub's width on the resonance frequency (a) $1^{\text {st }}$ and $5^{\text {th }}$ stub. (b) $2^{\text {nd }}$ and $4^{\text {th }}$ stub. (c) Middle stub

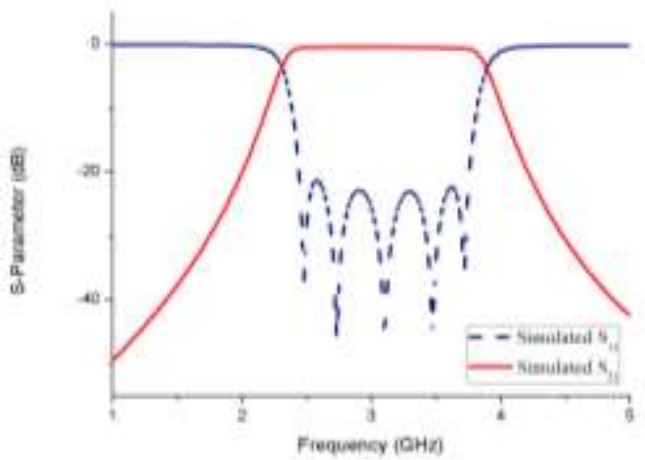

(a)

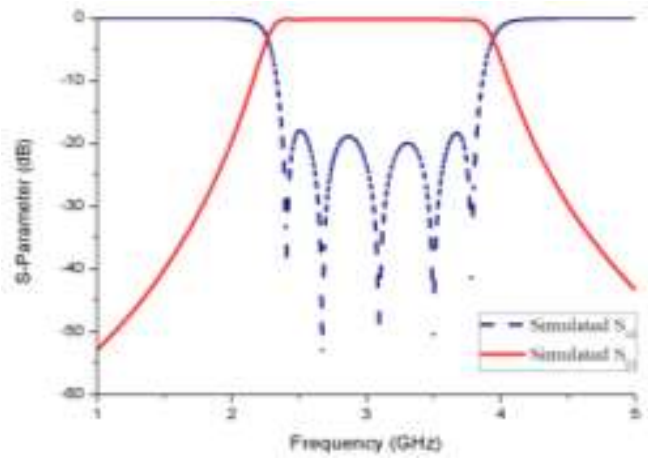

(b)

Figure 6. (a) Simulation results of ideal bandpass filter. (b) Simulation results of microstrip bandpass filter

\subsection{Defected microstrip structure}

In this section, DMS [24]-[25] is designed as a notch filter or band stop filter. There are several types of DMS such as C-shape, T-inversed shape, and U- Shape. Based on our study in [26], U-shaped structure is the most suitable one due to its high selectivity and strong insertion loss. Therefore, it was selected to be integrated with BPF in order to produce dual-band BPF. The structure of U-shaped DMS is shown in Figure 7. It comprises of horizontal and vertical slot in the middle of conductor line. In the center of the rectangular microstrip line is defected with U-shaped stub. The width and length of both branches of the U-shaped is indicated as $l_{2} \times h_{2}$. Meanwhile, $h_{3}$ is stated as the detachment between the branches of the Ushaped. The lower section of the U-shaped is defected with the width of $h_{4}$. Figure 8 shows the simulation results of the U-shaped DMS. It achieves an attenuation level $\left(S_{21}\right)$ better than $-30 \mathrm{~dB}$, return loss $\left(\mathrm{S}_{11}\right)$ of -0.2 $\mathrm{dB}$ at $3 \mathrm{GHz}$. 


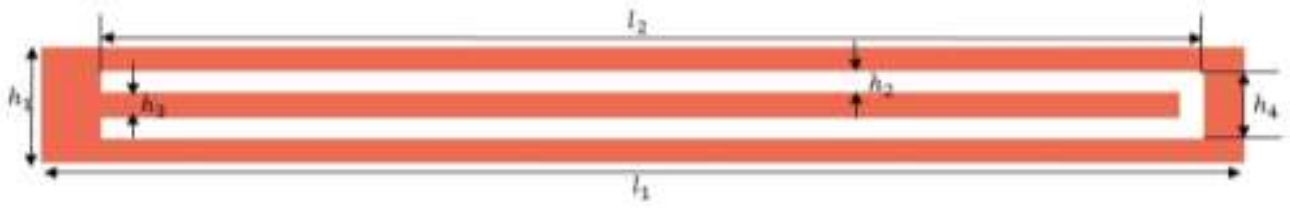

Figure 7. U-shaped DMS structure

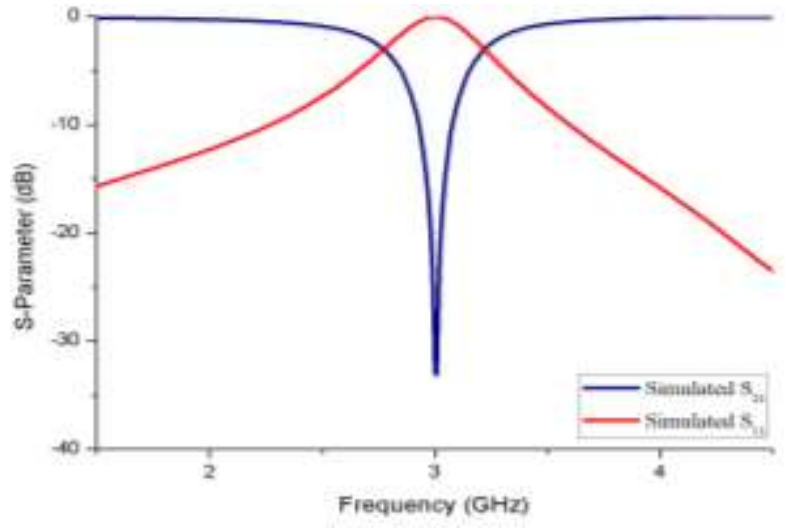

Figure 8. Simulation results of U-shaped DMS

\section{INTEGRATION OF BANDPASS FILTER WITH U-SHAPED DMS}

In this section, BPF is integrated with U-shaped DMS. Parametric analysis is conducted on the parameter of the number and position of U-shaped DMS filter as it is integrated within the wideband bandpass filter. The number and position of U-shaped DMS may affect the attenuation of the unwanted frequency band as it will be showed later in the following subsections. Table 3 shows the specifications of dual-band BPF.

Table 3. Specifications of dual-band bandpass filter

\begin{tabular}{cc}
\hline First Passband $(\mathrm{GHz})$ & $2.3-2.7$ \\
\hline Second Passband $(\mathrm{GHz})$ & $3.1-3.9$ \\
Return Loss $(\mathrm{dB})$ & $<-20$ \\
Insertion Loss $(\mathrm{dB})$ & $<-1$ \\
Cantered Notch $(\mathrm{GHz})$ & 3.0 \\
\hline
\end{tabular}

\subsection{BPF with one U-shaped DMS}

The integration between bandpass filter and one U-shaped DMS is shown in Figure 9. Parametric analysis is done by varying the position of U-shaped DMS along the transmission line of bandpass filter. The position of $d$ is varied from 16 to $26 \mathrm{~mm}$ with a step size of $5 \mathrm{~mm}$. From Figure 10, it can be observed that the distance $\mathrm{d}=16 \mathrm{~mm}$ from the Port 1 attained good performance in terms of return loss, insertion loss, and attenuation.

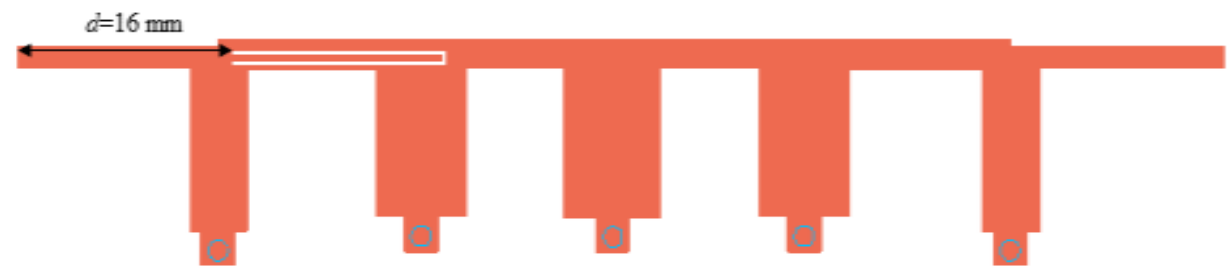

Figure 9. Bandpass filter with one U-shaped DMS 


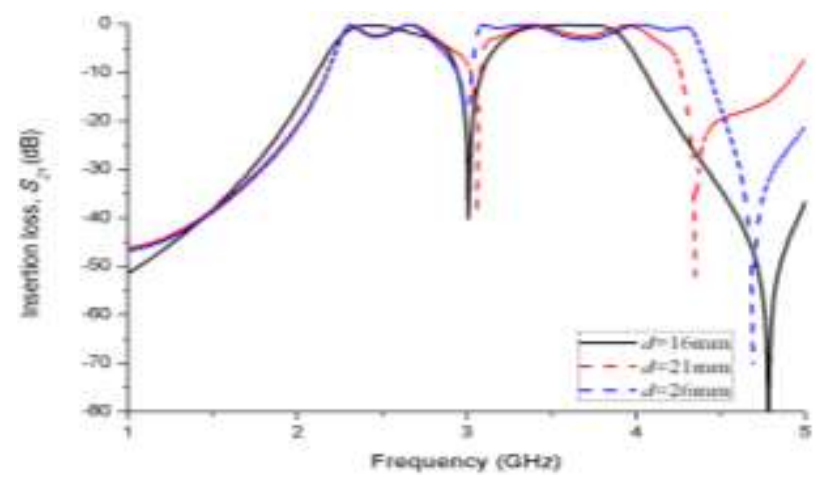

Figure 10. Effect of notch response with variation of $d$

\subsection{BPF with two U-shaped DMS}

In this section, two U-shaped DMS is integrated with bandpass filter for performance enhancement as shown in Figure 11. Figure 12 shows the comparison of the simulated response of the designed bandpass filter with one DMS and two DMSs. It is identified that the notch response is 44\% improved with two DMSs at center frequency of $3 \mathrm{GHz}$ with the attenuation level of $68 \mathrm{~dB}$ compared to one DMS. The simulated two passbands for two DMSs has been found to be at the center frequencies of $2.45 \mathrm{GHz}$ and $3.6 \mathrm{GHz}$ with the fractional bandwidth of $16 \%$ and $16.7 \%$ respectively. The simulated return and insertion losses are greater than $20 \mathrm{~dB}$ and better than $1 \mathrm{~dB}$, respectively. It is Proven that the integration of two DMSs has enhanced the design response.

The integration of BPF with two U-shaped DMS is fabricated using Roger 4350B. The fabricated device occupied an area of $89.5 \times 13.2 \mathrm{~mm} 2$ as shown in Figure 13. Figure 14(a) shows the comparison between the simulated and fabricated responses of the designed filter. Good agreement can be observed between the simulated and measured results with slight deviation due to fabrication tolerance. The dual-band BPF operates at $2.51 \mathrm{GHz}$ and $3.59 \mathrm{GHz}$ with $3-\mathrm{dB}$ fractional bandwidth of $15.94 \%$ and $15.86 \%$, respectively. The measured return losses are better than $15 \mathrm{~dB}$, while the measured insertion losses are better than $1 \mathrm{~dB}$. Group delay for both simulated and measured response of dual-band bandpass filter is shown in Figure 12(b). The measured group delay is discovered quite flat and smooth in the overall band aside from the notch band.

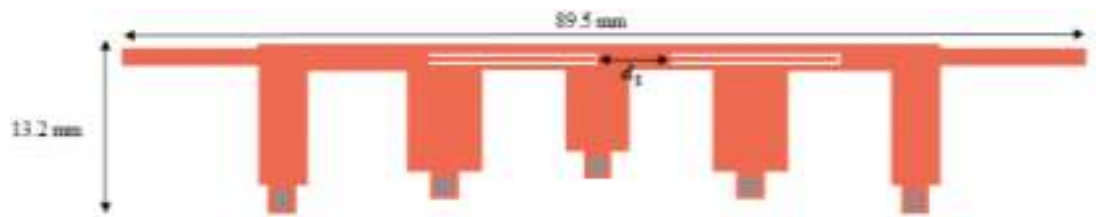

Figure 11. Bandpass filter with two U-shaped DMS

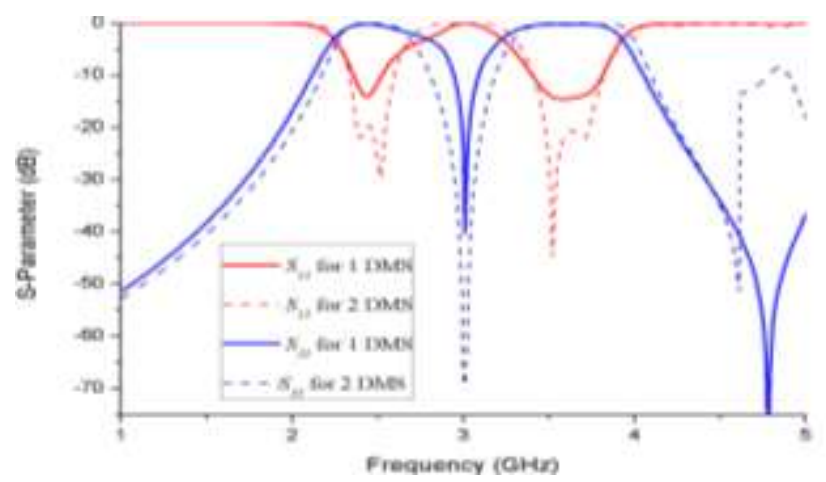

Figure 12. Performance comparison of simulated response of dual-band Bandpass filter with one and two DMSs 


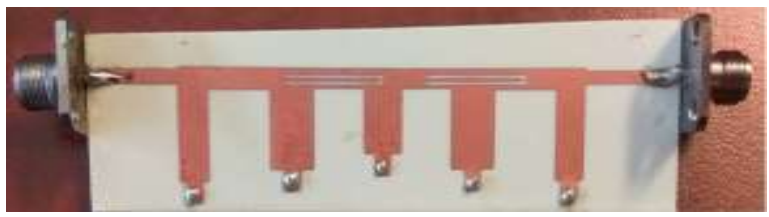

Figure 13. Fabricated board of the designed dual-band bandpass filter

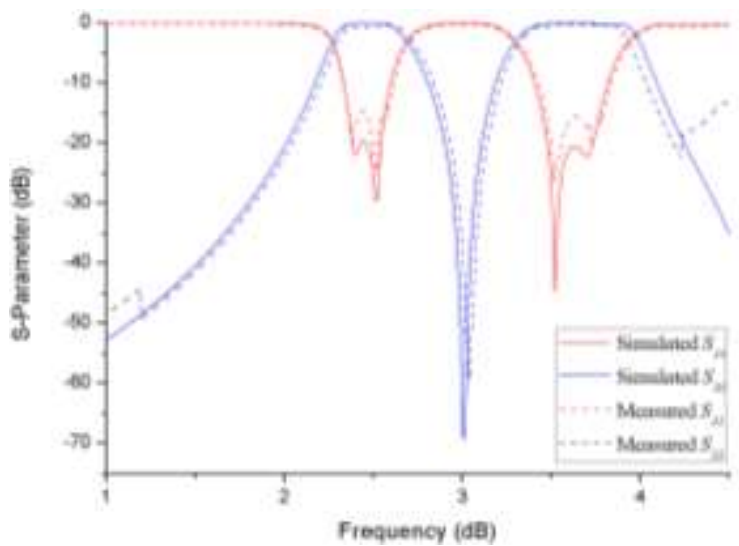

(a)

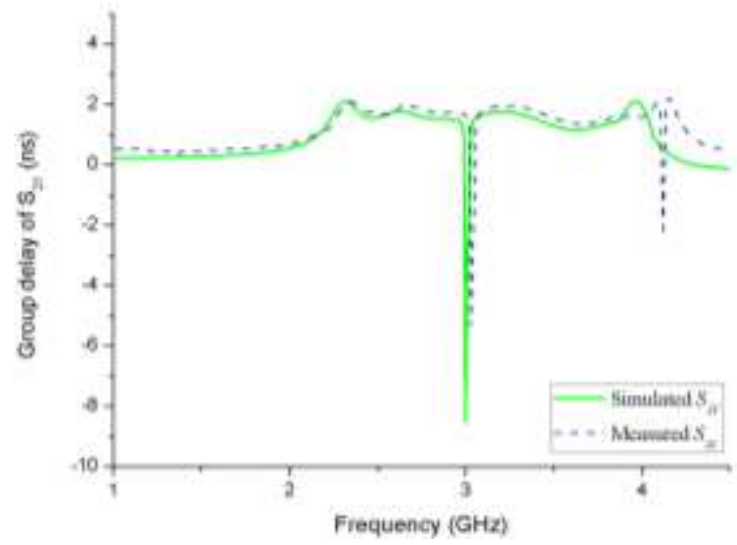

(b)

Figure 14. (a) Performance comparison between simulated and measured response of dual-band bandpass filter, (b) Comparison of group delay between simulated and measured response of dual-band bandpass filter

\section{CONCLUSION}

In conclusion, dual-band bandpass filter based on an integration of conventional short circuit stubs bandpass filter and two U-shaped DMS has been designed successfully. Advanced design system has been used to simulate the designed circuit. Roger $4350 \mathrm{~B}$ board has been used to fabricate the designed filter. The design process started with designing five section quarter-wavelength short circuit stubs bandpass filter. Then, U-shaped DMS is designed as a band stop filter to produce a notch response at $3 \mathrm{GHz}$. Finally, an integration between U-shaped DMS and bandpass filter to produce dual-band response. Parametric analysis has been conducted on the position and number of U-shaped DMS to study their effect. It has been found that two U-shaped DMS separated by distance $\mathrm{d}=16 \mathrm{~mm}$ yielded an improvement in the notch response by $44 \%$. Where, $70 \mathrm{~dB}$ attenuation level has been achieved with two DMS, while $40 \mathrm{~dB}$ is achieved with one DMS at center frequency of $3 \mathrm{GHz}$. The proposed filter achieves two pass bands operated at $2.51 \mathrm{GHz}$ and $3.59 \mathrm{GHz}$ with $3-\mathrm{dB}$ fractional bandwidths of $15.94 \%$ and $15.86 \%$, respectively. Further study can be undertaken for triple-passband wide bandwidth with electronically tunable.

\section{ACKNOWLEDGEMENTS}

The authors gratefully acknowledge Universiti Teknikal Malaysia Melaka (UTeM) under the Zamalah Scheme for supporting this research work.

\section{REFERENCES}

[1] Z. Zakaria, et al., "Recent trends on dual-and triple-band microwave filters for wireless communications," Australian Journal of Basic and Applied Sciences, vol. 7, no. 10, pp. 235-243, Aug. 2013.

[2] M. A. Abdalla, A. M. Ahmed, and A. M. M. Allam, "A multiband filter for wireless and RFID applications," 2014 International Conference on Engineering and Technology (ICET), Cairo, pp. 1-4, 2014, doi: 10.1109/ICEngTechnol.2014.7016763.

[3] J. Hinojosa, et al., "Modified split-ring resonator for microstrip dual- band notch filter," 2015 European Microwave Conference (EuMC), Paris, pp. 813-816, 2015, doi: 10.1109/EuMC.2015.7345888.

[4] M. F. A. Khalid, et al., "Dual-band bandpass filter with rectangular shaped defective ground structure," 2015 IEEE International RF and Microwave Conference (RFM), Kuching, pp. 35-39, 2015, doi: 10.1109/RFM.2015.7587707. 
[5] Mussa Mabrok, et al., "Microwave Bandpass Filter Integrated with Notch Response for Wide-band Applications," Indonesian Journal of Electrical Engineering and Computer Science (IJEECS), vol. 11, no. 2, pp. 797-804, 2018, doi: 10.11591/ijeecs.v11.i2.pp797-804.

[6] Q. Chu and F. Chen, "A Compact Dual-Band Bandpass Filter Using Meandering Stepped Impedance Resonators," IEEE Microwave and Wireless Components Letters, vol. 18, no. 5, pp. 320-322, May 2008, doi: 10.1109/LMWC.2008.922117.

[7] H. W. Liu, et al., "Compact dual-band bandpass filter using defected microstrip structure for GPS and WLAN applications," Electronics Letters, vol. 46, no. 21, pp. 1444-1445, October 2010, doi: 10.1049/el.2010.2146.

[8] W.-Y. Chen, et al., "A New Tri-Band Bandpass Filter for GSM, WiMAX and Ultra-Wideband Responses by Using Asymmetric Stepped Impedance Resonators," Progress In Electromagnetics Research, vol. 124, pp. 365-381, 2012, doi: 10.2528/PIER11122010.

[9] W. Chen, Y. Zhao, and Z. Jun, "Compact and Wide Upper-Stopband Triple-Mode Broadband Microstrip BPF," TELKOMNIKA (Telecommunication Computing Electronics and Control), vol. 10, no. 2, pp. 353-358, 2012, doi: 10.12928/telkomnika.v10i2.805.

[10] S. Zhang and L. Zhu, "Synthesis Design of Dual-Band Bandpass Filters with $\lambda / 4$ Stepped-Impedance Resonators," IEEE Transactions on Microwave Theory and Techniques, vol. 61, no. 5, pp. 1812-1819, 2013, doi: 10.1109/TMTT.2013.2256143.

[11] Y. -. Lu, C. -. Hua, and T. -. Liu, "A novel dual-band bandpass filter with C-section loaded resonators," 2015 AsiaPacific Microwave Conference (APMC), Nanjing, pp. 1-3, 2015, doi: 10.1109/APMC.2015.7413139.

[12] Z. Zhang, Q. Chu, and F. Chen, "Compact Dual-Band Bandpass Filters Using Open-/Short-Circuited Stub-Loaded N/4 Resonators," in IEEE Microwave and Wireless Components Letters, vol. 25, no. 10, pp. 657-659, Oct. 2015, doi: 10.1109/LMWC.2015.2463216.

[13] Jianwei Liu, et al., "Compact tri-band bandpass filter using asymmetric square ring loaded resonator," 2016 IEEE MTT-S International Microwave Workshop Series on Advanced Materials and Processes for RF and THz Applications (IMWS-AMP), Chengdu, pp. 1-3, 2016, doi: 10.1109/IMWS-AMP.2016.7588429.

[14] F. Wei, P. Qin, Y. J. Guo, and X. Shi, "Design of multi-band bandpass filters based on stub loaded steppedimpedance resonator with defected microstrip structure," IET Microwaves, Antennas \& Propagation, vol. 10, no. 2, pp. 230-236, 2016, doi: 10.1049/iet-map.2015.0495.

[15] E. S. Ahmed, "Compact Dual-Band Parallel Coupled T-Shaped SIR Filter for WLAN Applications, "TELKOMNIKA (Telecommunication Computing Electronics and Control), vol. 15, no. 4, pp. 1677-1681, 2017, doi: 10.12928/telkomnika.v15i4.5584.

[16] Mussa Mabrok, et al., "Microwave Bandpass Filter Integrated with Notch Response for Wide-band Applications," Indonesian Journal of Electrical Engineering and Computer Science (IJEECS), vol. 11, no. 2, pp. 797-804, 2018, doi: 10.11591/ijeecs.v11.i2.pp797-804.

[17] L. Wang, Y. Xiong, L. Gong, M. Zhang, H. Li, and X. Zhao, "Design of Dual-Band Bandpass Filter With Multiple Transmission Zeros Using Transversal Signal Interaction Concepts," IEEE Microwave and Wireless Components Letters, vol. 29, no. 1, pp. 32-34, 2019, doi: 10.1109/LMWC.2018.2884147.

[18] Mussa Mabrok, et al., "Switchable Dual-band Bandpass Filter Based on Stepped Impedance Resonator with UShaped Defected Microstrip Structure for Wireless Applications," TELKOMNIKA (Telecommunication Computing Electronics and Control), vol. 17, no. 2, pp. 1032-1039, 2019, doi: 10.12928/telkomnika.v17i2.11637.

[19] Nurshamimi Rosli, et al., "Design of compact multi-mode microstrip resonator filters for dual-band application," Indonesian Journal of Electrical Engineering and Computer Science (IJEECS), vol. 13, no. 2, pp. 696-701, 2019, doi: 10.11591/ijeecs.v13.i2.pp696-701.

[20] Jenan Ayad and Mustafa A. Jalil, "Design of dual-mode SIR bandpass filter based on shorting pin for wireless communication applications," Indonesian Journal of Electrical Engineering and Computer Science (IJEECS), vol. 18, no. 3, pp. 1375-1382, 2020, doi: 10.11591/ijeecs.v18.i3.pp1375-1382.

[21] G. Liang and F. Chen, "A Compact Dual-Wideband Bandpass Filter Based on Open-/Short-Circuited Stubs," IEEE Access, vol. 8, pp. 20488-20492, 2020, doi: 10.1109/ACCESS.2020.2968518.

[22] X. Guo, L. Zhu, and W. Wu, "Design Method for Multiband Filters with Compact Configuration in Substrate Integrated Waveguide," in IEEE Transactions on Microwave Theory and Techniques, vol. 66, no. 6, pp. 3011-3018, June 2018, doi: 10.1109/TMTT.2018.2830337.

[23] Ian Hunter, "Theory and Design of Microwave Filters", Institution of Electrical Engineers, 2001, doi: 10.1049/pbew048e.

[24] J. Xiao and W. Zhu, "New Defected Microstrip Structure Bandstop Filter," Progress In Electromagnetics Research Symposium Proceedings, vol. 1, pp. 1471-1474, 2011, doi: 10.1109/PIERS.2017.8261855.

[25] D. Cheng, H.-C. Yin, and H.-X. Zheng, "Investigation on a Defected Microstrip Structure and Applications in Designing Microstrip Filters, "Journal of Electromagnetic Waves and Applications, vol. 26, no.10, pp. 37-41, 2012, doi: 10.1080/09205071.2012.699401.

[26] Mussa Mabrok, et al., "Effect of the defected microstrip structure shapes on the performance of dual-band bandpass filter for wireless communications, "Bulletin of Electrical Engineering and Informatics (BEEI), vol. 10, no. 1, pp. 232-240, doi: 10.11591/eei.v10i1.2662 222222240240, 2020. 